\title{
Tannic acid-modified silver nanoparticles enhance the anti-Acanthamoeba activity of three multipurpose contact lens solutions without increasing their cytotoxicity
}

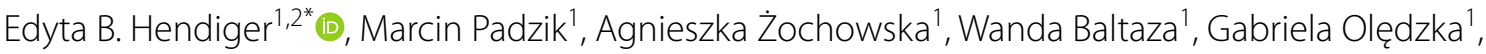 \\ Diana Zyskowska', Julita Bluszcz' , Sylwia Jarzynka', Lidia Chomicz' , Marta Grodzik3 , Jacek Hendiger ${ }^{4}$, \\ José E. Piñero ${ }^{2}$, Jarosław Grobelny ${ }^{5}$, Katarzyna Ranoszek-Soliwoda ${ }^{5}$ and Jacob Lorenzo-Morales ${ }^{2}$
}

\begin{abstract}
Background: Free-living amoebae of the genus Acanthamoeba are cosmopolitan, widely distributed protozoans that cause a severe, vision-threatening corneal infection known as Acanthamoeba keratitis (AK). The majority of the increasing number of AK cases are associated with contact lens use. Appropriate eye hygiene and effective contact lens disinfection are crucial in the prevention of AK because of the lack of effective therapies against it. Currently available multipurpose contact lens disinfection systems are not fully effective against Acanthamoeba trophozoites and cysts. There is an urgent need to increase the disinfecting activity of these systems to prevent AK infections. Synthesized nanoparticles (NPs) have been recently studied and proposed as a new generation of anti-microbial agents. It is also known that some plant metabolites, including tannins, have anti-parasitic activity. The aim of this study was to evaluate the anti-amoebic activity and cytotoxicity of tannic acid-modified silver NPs (AgTANPs) conjugated with selected multipurpose contact lens solutions.
\end{abstract}

Methods: The anti-amoebic activities of pure contact lens care solutions, and NPs conjugated with contact lens care solutions, were examined in vitro by a colorimetric assay based on the oxido-reduction of alamarBlue. The cytotoxicity assays were performed using a fibroblast HS-5 (ATCC CRL-1 1882) cell line. The results were statistically analysed by ANOVA and Student-Newman-Keuls test using $P<0.05$ as the level of statistical significance.

Results: We show that the NPs enhance the anti-Acanthamoeba activities of the tested contact lens solutions without increasing their cytotoxicity profiles. The activities are enhanced within the minimal disinfection time recommended by the manufacturers.

Conclusions: The conjugation of the selected contact lens solutions with AgTANPs might be a novel and promising approach for the prevention of AK infections among contact lens users.

Keywords: Acanthamoeba keratitis, Contact lens solutions, Silver nanoparticles, Tannic acid

*Correspondence: edyta.hendiger@wum.edu.pl

${ }^{1}$ Laboratory of Parasitology, Department of Medical Biology, Medical

University of Warsaw, 14/16 Litewska Street, 00-575 Warsaw, Poland

Full list of author information is available at the end of the article

c) The Author(s) 2020. This article is licensed under a Creative Commons Attribution 4.0 International License, which permits use, sharing, adaptation, distribution and reproduction in any medium or format, as long as you give appropriate credit to the original author(s) and the source, provide a link to the Creative Commons licence, and indicate if changes were made. The images or other third party material in this article are included in the article's Creative Commons licence, unless indicated otherwise in a credit line to the material. If material is not included in the article's Creative Commons licence and your intended use is not permitted by statutory regulation or exceeds the permitted use, you will need to obtain permission directly from the copyright holder. To view a copy of this licence, visit http://creativeco mmons.org/licenses/by/4.0/. The Creative Commons Public Domain Dedication waiver (http://creativecommons.org/publicdomain/ zero/1.0/) applies to the data made available in this article, unless otherwise stated in a credit line to the data. 


\section{Background}

Amoebae of the genus Acanthamoeba are free-living, abundant and cosmopolitan protozoans that show various degrees of pathogenicity to humans. They are ubiquitous in both natural and manmade environments. As facultative human parasites, when transmitted from the environment to the eye surface, they may cause a progressive, sight-threatening corneal infection known as Acanthamoeba keratitis (AK) [1-5]. Improper use and disinfection of contact lenses, corneal damage, and exposure of the eyes to water polluted with Acantham$o e b a$ are the primary risk factors of AK. The lack of specific symptoms in the early stages of the infection, and co-infections with other microorganisms, cause serious diagnostic difficulties and a delay in treatment. The number of AK infections has been increasing worldwide. Current therapeutic approaches are limited to the prolonged application of diamidines and biguanides. However, these treatments are not specific and are very toxic to the eye [6-9]. Amoebic trophozoites may attach to the surface of both contact lenses and contact lens storage cases. Multipurpose contact lens disinfection systems are not effective against Acanthamoeba and their anti-amoebic activity needs improvement [10-12]. In summary, prevention, including proper eye hygiene and effective contact lens disinfection, seems to be the best approach to limiting the incidence of AK.

In recent years, the fast development of nanotechnology has been observed. Synthetised nanoparticles (NPs) are currently proposed as a new generation of anti-bacterial, anti-viral and anti-fungal agents [13, 14]. Moreover, NP activity against different protozoans such as Giardia intestinalis, Entamoeba histolytica, Cryptosporidium parvum and Leishmania spp. has been already confirmed [15-17]. Plant metabolites, including tannins, present anti-microbial activity $[18,19]$. They are capable of forming insoluble complexes with nucleic acids, carbohydrates, proteins and chelating metal ions. Tannic acid (penta-m-digalloyl glucose) is the simplest polyphenolic, hydrolysable plant metabolite with confirmed anti-bacterial, anti-cancer and anti-oxidant activity [20-23]. In our previous studies we demonstrated that tannic acidmodified silver NPs (AgTANPs) were well absorbed and showed anti-amoebic activity against Acanthamoeba strains belonging to the T4 genotype [24]. Other authors have confirmed that NPs enhance the anti-amoebic effect of biguanides such as chlorhexidine digluconate and other therapeutic compounds [25-27]. The aim of this study was to evaluate the activity and cytotoxicity of AgTANPs conjugated with selected multipurpose contact lens solutions against the trophozoite stage of a strain of Acanthamoeba castellanii belonging to the T4 genotype.

\section{Methods}

\section{Cultivation of the strain}

Acanthamoeba castellanii Neff strain ATCC 30010 was cultured axenically in $25-\mathrm{cm}^{2}$ culture tissue flasks, without shaking, at $27{ }^{\circ} \mathrm{C}$ in PYG medium $[0.75 \%(\mathrm{w} / \mathrm{v})$ proteose peptone, $0.75 \%(\mathrm{w} / \mathrm{v})$ yeast extract and $1.5 \%$ $(\mathrm{w} / \mathrm{v})$ glucose] containing gentamicin $(10 \mathrm{mg} / \mathrm{ml})$, at the Department of Medical Biology, Medical University of Warsaw, Poland. The culture was sub-cultured twice a month and growth assessed using direct light microscopy and a Bürker chamber (haemocytometer).

\section{Nanoparticles}

AgTANPs were synthesized by a chemical reduction method using silver nitrate $\left(\mathrm{AgNO}_{3}\right.$; purity $99.999 \%$; Sigma-Aldrich, St Louis, MO). AgTANPs were prepared by mixing a heated aqueous solution of $\mathrm{AgNO}_{3}(95.2 \mathrm{~g}$, $0.017 \%)$ with an aqueous solution of a tannic acid (0.6 g, $5 \% \mathrm{C}_{76} \mathrm{H}_{52} \mathrm{O}_{46}$; Sigma-Aldrich). The long-term stability of the colloidal dispersions of all tested NPs ( $\zeta$ potential) was measured and confirmed by the electrophoretic light-scattering method with a Zetasizer Nano ZS (model ZEN3500; Malvern Instruments, Worcestershire, UK) $[26,28]$. The size and shape of the AgTANPs were determined by high-resolution scanning transmission electron microscopy (HR-STEM) (Fig. 1). Measurements were taken with a scanning electron microscope (Nova NanoSEM 450; FEI) using transmission mode (STEM II) at an accelerating voltage of $30 \mathrm{kV}$. Samples for HRSTEM investigations were prepared as follows: a drop of colloid was deposited onto carbon-coated copper grids (300 mesh) and left for $2 \mathrm{~h}$ for solvent evaporation. The well-dispersed nanofluids were used as a stock solution and were appropriately diluted to various concentrations ranging between $0.25-2.5$ p.p.m. and used in subsequent activity and cytotoxicity assays.

\section{Contact lens solutions}

The multipurpose solutions used in this study represent the three most common types of solutions used for contact lens care in Poland, namely Solo Care Aqua (SCA), Opti-Free (O-F) and ReNu MultiPlus $(\mathrm{ReNu})$. The tested contact lens care solutions and their ingredients are included in Table 1. All multipurpose solutions used in the study were purchased from authorized agents.

\section{Activity assays}

Pure contact lens solutions, and NPs at concentrations of $0.25,0.5,1.25$ and 2.5 p.p.m. conjugated with the contact lens care solutions, were examined in vitro and assessed 
for their anti-amoebic activity. To determine the antiamoebic efficacy on trophozoites (log growth phase after 6 days following sub-culturing), the previously described colorimetric 96-well microtitre plate assay, based on the oxido-reduction of alamarBlue, was used [29]. Subsequently, the plates were analysed over a period of $6 \mathrm{~h}$, $24 \mathrm{~h}, 48 \mathrm{~h}, 72 \mathrm{~h}$ and $96 \mathrm{~h}$ in a Synergy HTX Multimode Microplate Reader (BioTek) using the Gen5 software programme, a test wavelength of $570 \mathrm{~nm}$ and a reference wavelength of $630 \mathrm{~nm}$ in order to calculate the inhibition curves of the analysis. All experiments were performed three times, in triplicate. Amoebae growth and viability (trophozoite movement and presence of acanthopodia) in both control and tested assays were visualized by an Evos FLoid Cell Imaging System (ThermoFisher).

\section{Cytotoxicity}

Briefly, the cytotoxicity assays were performed using a fibroblast HS-5 (ATCC CRL-11882) cell line as described in our previous study [24]. A commercial kit for the evaluation of drug-induced cytotoxic effects based on the measurement of lactate dehydrogenase (LDH) activity released to the media (Pierce LDH cytotoxicity assay kits 88953,88954 ) was used as per protocol. The fibroblasts were incubated with each of the contact lens solutions separately and the contact lens solution plus NPs added at the same concentration as in the activity assays. To calculate the percent cytotoxicity, absorbance was measured at $490 \mathrm{~nm}$ and $680 \mathrm{~nm}$.

\section{Statistical analysis}

All experiments were performed three times in triplicate. SD and mean values were calculated for all activity and cytotoxicity data. The results were statistically analysed by ANOVA and Student-Newman-Keuls test using $P<0.05$ as the level of statistical significance.

\section{Results}

\section{Activity}

Our initial results confirmed the insufficient anti-amoebic effect of the tested contact lens solutions against Acanthamoeba trophozoites. Anti-amoebic activity was revealed for SCA and reached 32\% inhibition after $6 \mathrm{~h}$ of incubation. ReNu and O-F did not show an anti-amoebic effect on the tested Acanthamoeba strain within the first $24 \mathrm{~h}$ of incubation. The detailed data are shown in Table 2.

AgTANPs significantly enhanced anti-Acanthamoeba activity of the tested contact lens solutions. Specifically, AgTANPs conjugated with SCA showed the most

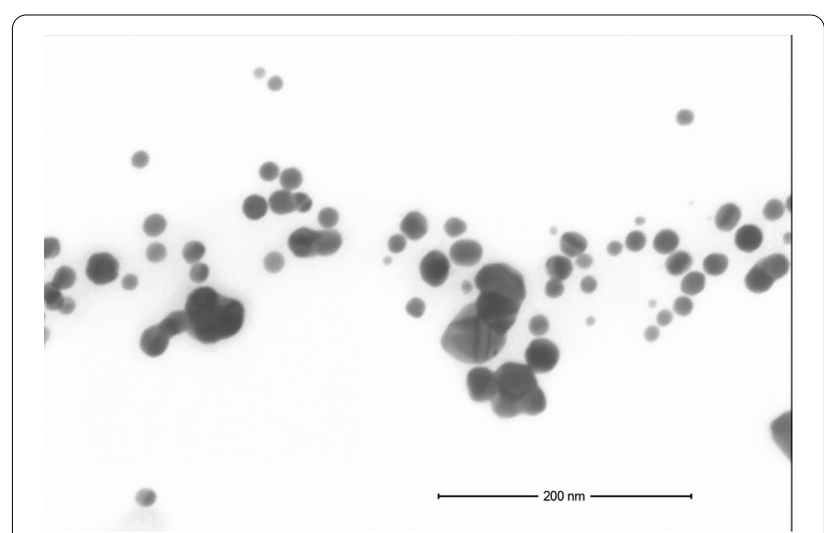

Fig. 1 High-resolution scanning transmission electron microscopy image of the distribution and diameters of the tannic acid-modified silver nanoparticles (AgTANPs)

promising dose-dependent increase of amoebae inhibition after the minimal disinfection time recommended by the manufacturers (6 h) (Fig. 2). A similar anti-amoebic effect was achieved for AgTANPs conjugated with $\mathrm{ReNu}$ (Fig. 3). The enhanced anti-amoebic effect of both conjugates lasted up to $96 \mathrm{~h}$ of incubation. O-F conjugated with the NPs did not show any enhanced effect during the first $24 \mathrm{~h}$ of incubation (Fig. 4). The anti-amoebic effects were revealed just after $48 \mathrm{~h}$ of incubation. The detailed results are shown in Table 2.

Compared to the control culture (Fig. 5a), $6 \mathrm{~h}$ of incubation with AgTANPs did not influence the morphology or the viability of the amoebae at the level of microscopic observation used here. Incubation with SCA caused decreased mobility of the trophozoites. Observed acanthopodia were less extensive than in the control cultures. Fragments of the disrupted cells were visualized between viable trophozoites (Fig. 5a). After $6 \mathrm{~h}$ of incubation with AgTANPs conjugated with SCA, morphological degeneration of the trophozoites developed (Fig. 5d). The size of the cells and the number of visible acanthopodia were lower compared to the assays illustrated in Fig. 5a-c. There were more disrupted cell fragments visualized. Some trophozoites started developing into rounded forms.

\section{Cytotoxicity}

The overall cytotoxicity measured for SCA and O-F was similar and reached $36 \%$. The cytotoxicity of $\mathrm{ReNu}$ reached $26 \%$. Cytotoxicity values for NPs conjugated with the contact lens solutions were not statistically significantly different from those of the pure contact lens solutions. The cytotoxicity results are listed in Table 3. 
Table 1 Ingredients of the multipurpose contact lens solutions and minimum disinfection times recommended by the manufacturers

\begin{tabular}{|c|c|c|c|}
\hline Manufacturer & Solution & Ingredients & $\begin{array}{l}\text { Minimum } \\
\text { disinfection } \\
\text { time (h) }\end{array}$ \\
\hline Bausch + Lomb & ReNu MultiPlus (ReNu) & $\begin{array}{l}\text { Hydranate (hydroxyalkylphosphonate) } 0.03 \% \text {, boric acid, edetate disodium, poloxam- } \\
\text { ine } 1 \% \text {, sodium borate, sodium chloride, preserved with Dymed (polyaminopropyl } \\
\text { biguanide } 0.0001 \% \text { ) }\end{array}$ & 4 \\
\hline Alcon & Opti-Free (O-F) (RepleniSH) & $\begin{array}{l}\text { TearGlyde (Tetronic 1304, nonanoyl ethylenediaminetriacetic acid), Polyquad (polyqua- } \\
\text { ternium-1) } 0.001 \% \text {, Aldox (myristamidopropyl dimethylamine) } 0.0005 \%\end{array}$ & 6 \\
\hline Menicon & Solo Care Aqua (SCA) & $\begin{array}{l}\text { Polyhexanide } 0.0001 \% \text {, Hydrolock (dexpanthenol, sorbitol), sodium phosphate, trometh- } \\
\text { amine, poloxamer } 407 \text {, disodium edetate }\end{array}$ & 4 \\
\hline
\end{tabular}

\section{Discussion}

In recent years cases of AK have been increasingly diagnosed worldwide. The available anti-amoebic therapies are not fully effective against $\mathrm{AK}$, and often result in damaging cytotoxicity to the human eye. The main key predisposing factor for AK is contact lens use. Effective contact lens disinfection is the best approach to minimising the incidence of AK. In this study, we tested multipurpose contact lens disinfecting systems containing different active ingredients, but characterized by a similar mode of action, which result in cell membrane perturbation (Table 1). Our results confirmed a lack of amoebicidal activity for all the tested multipurpose contact lens solutions against the Acanthamoeba strain used here, in accordance with other publications revealing that the disinfecting capabilities of current contact lens solutions are insufficient [11, 12, 30-33].

Rapid developments in nanotechnology have significantly improved the anti-microbial potential of NPs, especially silver NPs (AgNPs) [14, 34, 35]. The specific mechanism of action of AgNPs is still not entirely understood; however, recent studies conducted on bacteria did shed more light on this process. We know that NPs cause damage to the cell membrane. Adhesion of NPs is based on the electrostatic attraction of the negatively charged cell membrane and positively or less negatively charged NPs. The interaction decreases the $\zeta$ potential and depolarizes the cell membrane. This process leads to the disruption of membrane permeability and an alteration of the respiratory functions of the cell, eventually leading to disruption of cell integrity [36]. After crossing the cell membrane, NPs can interact with DNA, RNA and proteins, altering both transcription and translation processes. The presence of NPs in the cell causes oxidative stress and disruption of enzymatic pathways due to the resultant free radicals. Altogether, NPs cause cytotoxic effects and finally lead to cell death. The cytotoxicity of AgNPs depends on their physicochemical properties

Table 2 Anti-amoebic activity of the pure contact lens solutions and tannic acid-modified silver nanoparticles (AgTANPs) conjugated with the contact lens solutions after 6-96 h of incubation (\% inhibition)

\begin{tabular}{llllrr}
\hline & $6 \mathrm{~h}$ & $24 \mathrm{~h}$ & $48 \mathrm{~h}$ & $72 \mathrm{~h}$ & $96 \mathrm{~h}$ \\
\hline SCA & $31.95 \pm 1.70$ & $23.15 \pm 3.93$ & $37.68 \pm 1.16$ & $51.65 \pm 2.75$ & $47.15 \pm 3.25$ \\
SCA + 2.5 p.p.m. AgTANPs & $61.18 \pm 1.34$ & $51.60 \pm 8.50$ & $59.79 \pm 11.19$ & $66.02 \pm 5.42$ & $61.9 \pm 2.41$ \\
SCA + 1.25 p.p.m. AgTANPs & $61.67 \pm 4.63$ & $42.79 \pm 19.26$ & $52.03 \pm 11.57$ & $60.42 \pm 4.25$ & $54.50 \pm 0.21$ \\
SCA + 0.5 p.p.m. AgTANPs & $54.91 \pm 3.89$ & $36.88 \pm 20.08$ & $47.33 \pm 10.25$ & $58.21 \pm 3.07$ & $72.77 \pm 1.71$ \\
SCA + 0.25 p.p.m. AgTANPs & $52.49 \pm 6.35$ & $35.45 \pm 10.65$ & $45.35 \pm 6.56$ & $55.95 \pm 1.15$ & $51.31 \pm 1.13$ \\
O-F & No activity & No activity & No activity & $35.74 \pm 0.95$ & $47.35 \pm 2.75$ \\
O-F 2.5 p.p.m. AgTANPs & $31.11 \pm 3.09$ & $21.83 \pm 4.85$ & $44.79 \pm 4.92$ & $59.58 \pm 1.14$ & $57.72 \pm 0.55$ \\
O-F + 1.25 p.p.m. AgTANPs & No activity & $4.50 \pm 11.51$ & $33.32 \pm 4.38$ & $52.78 \pm 0.98$ & $52.29 \pm 0.24$ \\
O-F + 0.5 p.p.m. AgTANPs & No activity & No activity & $16.63 \pm 3.70$ & $41.62 \pm 3.08$ & $41.15 \pm 2.46$ \\
O-F + 0.25 p.p.m. AgTANPs & No activity & No activity & No activity & $36.82 \pm 1.69$ & $36.74 \pm 1.77$ \\
ReNu & No activity & No activity & $24.23 \pm 4.88$ & $43.99 \pm 2.10$ & $46.76 \pm 0.64$ \\
ReNu 2.5 p.p.m. AgTANPs & $41.59 \pm 2.18$ & $36.63 \pm 4.69$ & $56.72 \pm 3.58$ & $67.45 \pm 2.68$ & $64.59 \pm 2.98$ \\
ReNu + 1.25 p.p.m. AgTANPs & $39.58 \pm 2.66$ & $31.17 \pm 5.28$ & $50.07 \pm 3.57$ & $62.77 \pm 2.79$ & $58.85 \pm 3.63$ \\
ReNu + 0.5 p.p.m. AgTANPs & $39.18 \pm 0.87$ & $22.60 \pm 7.05$ & $45.22 \pm 5.33$ & $61.90 \pm 2.21$ & $58.56 \pm 3.39$ \\
ReNu + 0.25 p.p.m. AgTANPs & $32.99 \pm 4.42$ & $13.47 \pm 0.14$ & $43.52 \pm 4.20$ & $62.12 \pm 7.68$ & $57.55 \pm 0.11$ \\
\hline
\end{tabular}




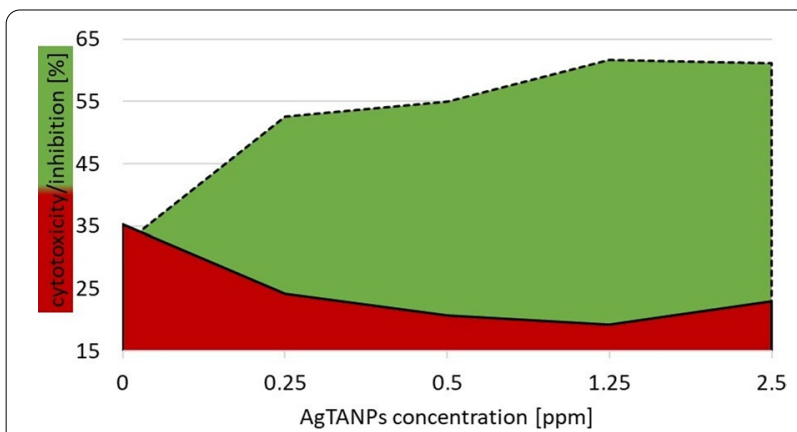

Fig. 2 Anti-Acanthamoeba activity of AgTANPs conjugated with Solo Care Aqua (SCA) contact lens solution after $6 \mathrm{~h}$ of incubation in relation to cytotoxicity

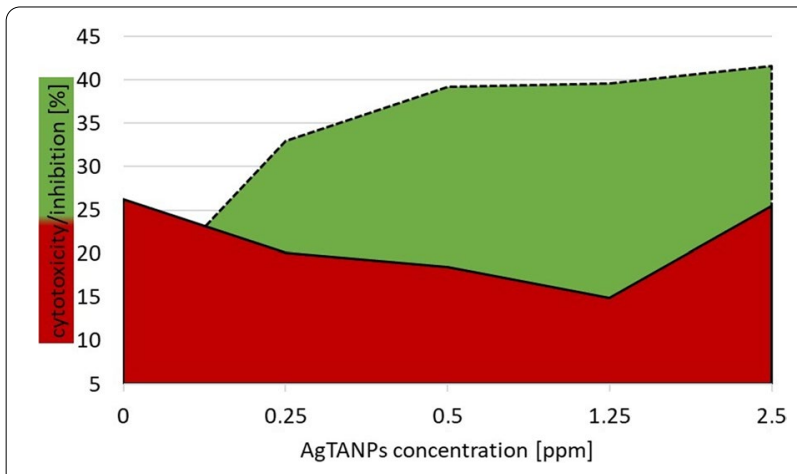

Fig. 3 Anti-Acanthamoeba activity of AgTANPs conjugated with ReNu MultiPlus contact lens solution after $6 \mathrm{~h}$ of incubation in relation to cytotoxicity

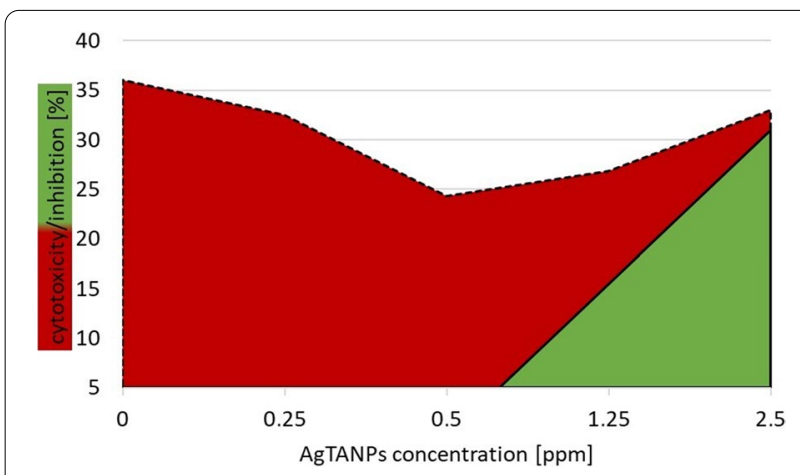

Fig. 4 Anti-Acanthamoeba activity of AgTANPs conjugated with Opti-Free contact lens solution after $6 \mathrm{~h}$ of incubation in relation to cytotoxicity

such as size and density. Typically, smaller NPs have a relatively increased stability and enhanced anti-microbial activity. Similarly, higher concentrations of NPs show increased anti-microbial activity. However, this property is strictly correlated to the tested microbial species and the type of NP used. The shape of a NP has not been proven to be a crucial factor influencing its anti-microbial activity. Some authors have shown that AgNPs with a truncated triangular shape, or similar geometry such as an hexagonal and octahedral shape, are more effective against bacteria, while other authors have reported that the shape of an AgNP does not have any influence on its activity [36-38]. Recent publications showed that NPs can prolong the ocular retention of some topical drugs, thus enabling treatment of eye diseases using reduced drug dosages $[39,40]$. It was confirmed that NPs coated onto the surface of contact lenses caused a significant reduction in the microbial colonization of the surface [41]. After $6 \mathrm{~h}$ of incubation, contact lenses impregnated with AgNPs did not exhibit desirable antibacterial activity against Staphylococcus aureus, although excellent anti-bacterial effects against Pseudomonas aeruginosa were demonstrated [42]. Silver-impregnated lens cases showed less microbial contamination compared to control cases. Most microorganisms isolated from silverimpregnated cases were members of the normal skin flora [43].

Only a few studies have examined the activity of NPs against Acanthamoeba spp. Cobalt NPs have been studied for their anti-amoebic potential, and hexagonal microflakes showed the most promising anti-Acanthamoeba effects compared to nanoflakes and granular cobalt NPs. Apart from their concentration and size, the composition and morphology of the tested noncompounds also determined their anti-amoebic activity [44, 45]. AgNPs are well absorbed by Acanthamoeba trophozoites and integrated into the cell matrix. NPs decrease the viability of trophozoites and alter their metabolic activity in a dose-dependent manner [46]. In our previous studies we confirmed that AgNPs conjugated with contact lens solutions showed dose-dependent enhanced anti-amoebic activity [47]. Recently published studies confirmed the enhanced anti-microbial effects of AgNPs and gold NPs (AuNPs) conjugated with commonly used drugs like chlorhexidine, fluconazole or amphotericin $\mathrm{B}$, as well as with some disinfectants $[27,48]$. Guanabenz, a drug that crosses the blood-brain barrier and has already been approved for the treatment of hypertension, showed significant anti-amoebic activity against both $A$. castellanii and Naegleria fowleri when conjugated with AuNPs and AgNPs. A significant reduction in host cytopathogenicity, especially for silver nanoconjugates, was revealed, and was associated with negligible cytotoxicity against human cells [49].

Environmentally friendly and cost-effective bio-nanotechnology techniques are being developed to produce anti-microbial active conjugates as potential candidates 


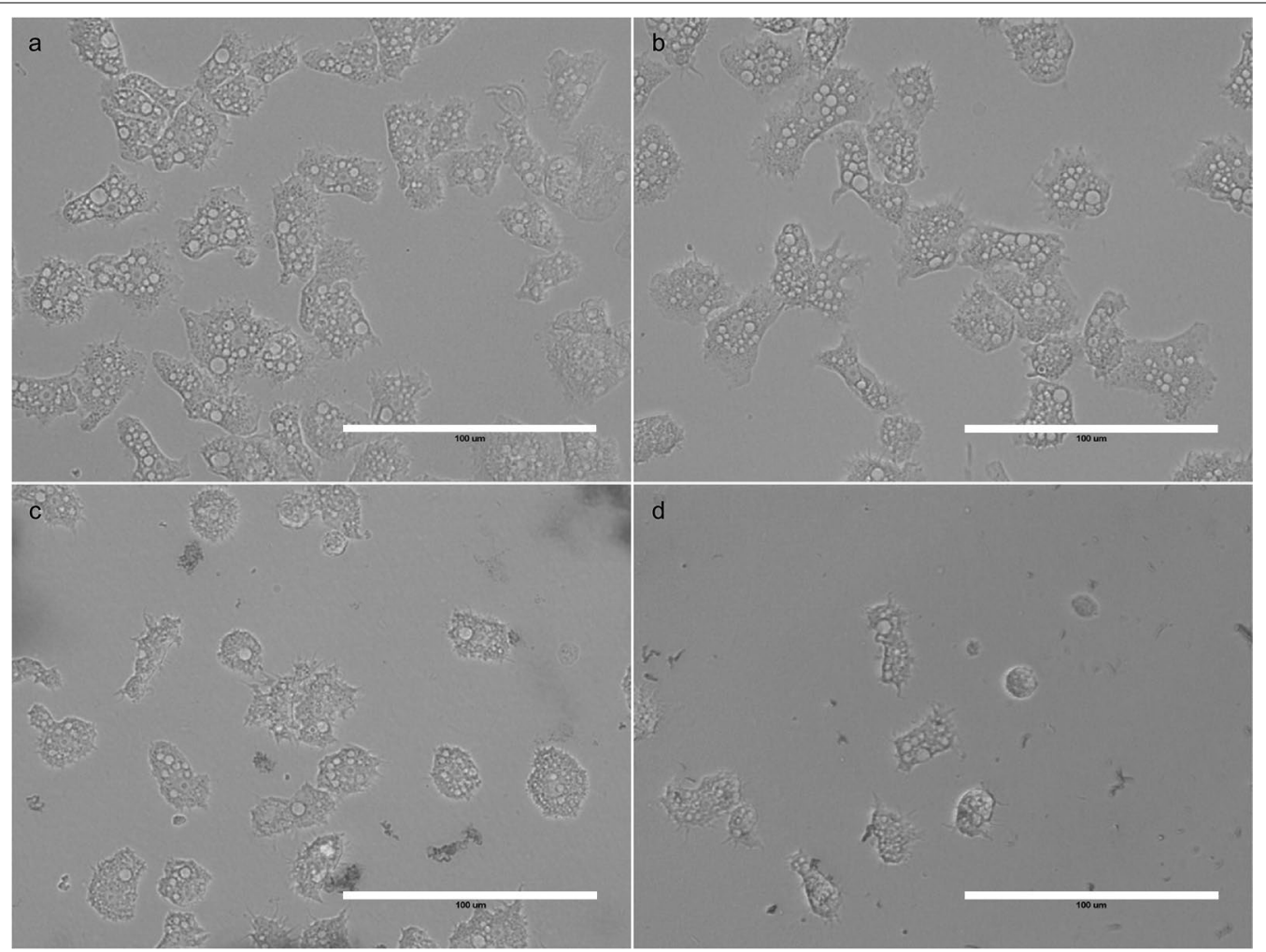

Fig. 5 a-d Acanthamoeba trophozoites after 6 h of incubation. a Control culture in PYG medium. b Incubation with AgTANPs. c Incubation with SCA. $\mathbf{d}$ Incubation with AgTANPs conjugated with SCA. The arrow shows a rounded form. All images $(\times 40)$ represent the population of treated amoebae and were taken under a live cell imaging microscope (EVOS FLoid Cell Imaging Station). For abbreviations, see Figs. 1 and 2

Table 3 Cytotoxicity of the contact lens solutions $(C L S)$ and the CLS conjugated with the AgTANPs (\%)

\begin{tabular}{llllll}
\hline & CLS & CLS + & CLS + & CLS + & CLS + \\
& & $\begin{array}{l}\text { 0.25 p.p.m. } \\
\text { AgTANPs }\end{array}$ & $\begin{array}{l}\text { 0.5 p.p.m. } \\
\text { AgTANPs }\end{array}$ & $\begin{array}{l}\text { 1.25 p.p.m. } \\
\text { AgTANPs }\end{array}$ & $\begin{array}{l}\text { 2.5 p.p.m. } \\
\text { AgTANPs }\end{array}$ \\
\hline SCA & 35.3 & 24.2 & 20.7 & 19.2 & 23.0 \\
O-F & 36.0 & 32.5 & 24.3 & 26.9 & 33.0 \\
ReNu & 26.2 & 20.1 & 18.5 & 15 & 25.5 \\
\hline
\end{tabular}

For other abbreviations, see Tables 1 and 2

for the eradication of infections and reduction of microbial contamination of medical devices including contact lenses. Products created by the integration and conjugation of bioactive agents with nanomaterials have been tested mainly for their anti-bacterial activities. AgNPs, AuNPs and platinum NPs produced by green synthesis showed enhanced anti-bacterial activity after combination with different classes of antibiotics [50]. The biosynthesis of AgNPs with an extract of Salvia spinosa resulted in increased bactericidal activity against Gram-positive and Gram-negative bacteria [51]. Novel conjugates using biogenic AgNPs from Convolvulus arvensi extract and chitosan showed anti-microbial, anti-biofilm, and anti-cancer potentialities [52]. An extract of Oscillatoria limnetica conjugated with AgNPs exhibited strong antibacterial activity against multidrug-resistant bacteria as well as cytotoxic effects against both a human breast cancer cell line and a human colon cancer cell line [53]. Synthesis of silver chloride NPs, using walnut green husk extract as well as AgNPs with Peganum harmala L. leaf extract resulted in significant inhibitory effects against clinical isolates of Escherichia coli and S. aureus [54, 55]. Bio-nanotechnology has not been extensively studied on protozoan species. There are just a few published studies focusing on the influence of NPs conjugated with plant extracts on amoebae. Jatropha curcas, Jatropha gossypifolia and Euphorbia milii extracts combined with NPs exhibited a significant reduction of Acanthamoeba trophozoites, with a low cytotoxic effect on human cells [25]. In our previous studies we confirmed that AgTANPs showed higher anti-amoebic activity and less cytotoxicity to human cells in comparison with pure AgNPs [24]. In the present study we revealed that AgTANPs conjugated with contact lens solutions exhibited even better antiamoebic activity in relation to cytotoxicity than in our previous studies where we tested pure AgNP conjugates [47]. We conclude that differences in the anti-amoebic 
activity of the tested conjugates may be mainly driven by the anti-amoebic activity of the pure contact lens solutions. NPs at the tested concentration seem to enhance the existing anti-amoebic potential of the selected contact lens solutions.

\section{Conclusions}

In this study, we showed dose-dependent enhancement of the anti-amoebic effect of AgTANPs conjugated with SCA and ReNu solutions against an Acanthamoeba T4 strain. These promising results were obtained within the minimal disinfection time recommended by the manufacturers $(6 \mathrm{~h})$ and without increased toxicity to human cells. In summary, conjugation of the selected contact lens solutions with AgTANPs might be a promising approach for the prevention of AK infections in contact lens users. However, further studies should be conducted to elucidate the stability of the conjugates and their activity against Acanthamoeba spp. cysts.

\begin{abstract}
Abbreviations
AK: Acanthamoeba keratitis; NPs: Nanoparticles; AgTANPs: Tannic acidmodified silver nanoparticles; HR-STEM: High-resolution scanning transmission electron microscopy; SCA: Solo Care Aqua; O-F: Opti-Free; ReNu: ReNu MultiPlus; AgNPs: Silver nanoparticles; AuNPs: Gold nanoparticles.
\end{abstract}

\section{Acknowledgements}

Not applicable.

\section{Authors' contributions}

Data curation: EBH, MP and AZ Formal analysis: EBH, MP, AZ and JH. Funding acquisition: MP, JEP and JLM. Investigation: EBH and A.Z. Methodology: EBH, MP, AZ, MG, JH, JG, KRS and JLM. Project administration: MP, GO and JLM. Resources: all authors. Supervision: MP and JLM. Writing (original draft): MP, EBH, JEP and JLM. Writing (all authors). Review and editing: MP, EBH and JLM. All authors read and approved the final manuscript.

\section{Funding}

This study was funded by grant NZI/PM1/18 of the Medical University of Warsaw. J. L. M. and J. E. P. were funded by PI18/01380 from the Instituto de Salud Carlos III, Spain and RICET [RD16/0027/0001 project, from the Programa Redes Temáticas de Investigación Cooperativa, FIS (Ministerio Español de Salud, Madrid, Spain)].

\section{Availability of data and materials}

The datasets used and/or analysed during the current study are available from the corresponding author on reasonable request.

\section{Ethics approval and consent to participate}

Not applicable.

\section{Consent for publication}

Not applicable.

\section{Competing interests}

The authors declare that they have no competing interests.

\section{Author details}

1 Laboratory of Parasitology, Department of Medical Biology, Medical University of Warsaw, 14/16 Litewska Street, 00-575 Warsaw, Poland. ${ }^{2}$ Instituto Universitario de Enfermedades Tropicales y Salud Pública de Canarias and Departamento de Obstetricia, Ginecología, Pediatría, Medicina Preventiva y Salud Pública, Toxicología, Medicina Legal y Forense y Parasitología, Universidad de La Laguna, Avenida Astrofísico Francisco Sánchez S/N, 38203 Tenerife, Spain. ${ }^{3}$ Department of Nanobiotechnology and Experimental Ecology, Institute of Biology, Warsaw, University of Life Sciences, 8 Ciszewskiego Street, 02-787 Warsaw, Poland. ${ }^{4}$ Faculty of Building Services, Hydro and Environmental Engineering, Warsaw University of Technology, 20 Nowowiejska Street, 00-653 Warsaw, Poland. ${ }^{5}$ Department of Materials Technology and Chemistry, Faculty of Chemistry, University of Lodz, 163 Pomorska Street, 90-236 Lodz, Poland.

Received: 28 August 2020 Accepted: 5 November 2020

Published online: 22 December 2020

\section{References}

1. Martinez AJ, Visvesvara GS. Free-living, amphizoic and opportunistic amebas. Brain Pathol. 1997;1:583-98.

2. Chomicz L, Padzik M, Graczyk Z, Starosciak B, Graczyk TK, Naprawska A, et al. Acanthamoeba castellanii: in vitro effects of selected biological, physical and chemical factors. Exp Parasitol. 2010;1:103-5.

3. Lorenzo-Morales J, Khan NA, Walochnik J. An update on Acanthamoeba keratitis: diagnosis, pathogenesis and treatment. Parasite. 2015;22:10.

4. Walochnik J, Scheikl U, Haller-Schober EM. Twenty years of Acanthamoeba diagnostics in Austria. J Eukaryot Microbiol. 2015;1:3-11.

5. Padzik M, Hendiger E, Szaflik J, Chomicz L. Amoebae of the genus Acanthamoeba - pathological agents in humans. Postep Mikrobiol. 2017:56:429-39.

6. Clarke B, Sinha A, Parmar DN, Sykakis E. Advances in the diagnosis and treatment of Acanthamoeba keratitis. J Ophthalmol. 2012;2012:484892.

7. Trabelsi H, Dendana F, Sellami A, Sellami H, Cheikhrouhou F, Neji S, et al. Pathogenic free-living amoebae: epidemiology and clinical review. Pathol Biol (Paris). 2012;6:399-405.

8. Lorenzo-Morales J, Martin-Navarro CM, Lopez-Arencibia A, Arnalich-Montiel F, Pinero JE, Valladares B. Acanthamoeba keratitis: an emerging disease gathering importance worldwide? Trends Parasitol. 2013;4:181-7.

9. Chomicz L, Conn DB, Padzik M, Szaflik JP, Walochnik J, Zawadzki PJ, et al. Emerging threats for human health in Poland: pathogenic isolates from drug resistant Acanthamoeba keratitis monitored in terms of their in vitro dynamics and temperature adaptability. Biomed Res Int. 2015;2015:231285.

10. Lonnen J, Kilvington S, Lam A, Heaselgrave W. 58 Biocidal efficacy of multipurpose contact lens disinfectant solutions against Acanthamoeba species. Cont Lens Anterior Eye. 2011;34:S30.

11. Padzik M, Chomicz L, Szaflik JP, Chruscikowska A, Perkowski K, Szaflik J. In vitro effects of selected contact lens care solutions on Acanthamoeba castellanii strains in Poland. Exp Parasitol. 2014;145(Suppl):S98-101.

12. Niyyati M, Sasani R, Mohebali M, Ghazikhansari M, Kargar F, Hajialilo E, et al. Anti-Acanthamoeba effects of silver and gold nanoparticles and contact lenses disinfection solutions. Iran J Parasitol. 2018;2:180-5.

13. Sondi I, Salopek-Sondi B. Silver nanoparticles as antimicrobial agent: a case study on E. coli as a model for Gram-negative bacteria. J Colloid Interface Sci. 2004;1:177-82.

14. Rzeszutek J, Matysiak-Kucharek M, Czajka M, Sawicki K, Rachubik P, Kruszewski M, et al. Application of nanoparticles and nanomaterials in medicine. Hygeia Public Health. 2014;49:449-57.

15. Said DE, Elsamad LM, Gohar YM. Validity of silver, chitosan, and curcumin nanoparticles as anti-Giardia agents. Parasitol Res. 2012;2:545-54.

16. Saad HA, Soliman Ml, Azzam AM, Mostafa B. Antiparasitic activity of silver and copper oxide nanoparticles against Entamoeba histolytica and Cryptosporidium parvum cysts. J Egypt Soc Parasitol. 2015;3:593-602.

17. Ullah I, Cosar G, Abamor ES, Bagirova M, Shinwari ZK, Allahverdiyev AM. Comparative study on the antileishmanial activities of chemically and biologically synthesized silver nanoparticles (AgNPs). 3 Biotech. 2018;2:98.

18. Sieniawska E. Activities of tannins-from in vitro studies to clinical trials. Nat Prod Commun. 2015;10:1877-84.

19. Chung KT, Wong TY, Wei Cl, Huang YW, Lin Y. Tannins and human health: a review. Crit Rev Food Sci Nutr. 1998;38:421-64.

20. Athar M, Khan WA, Mukhtar H. Effect of dietary tannic acid on epidermal, lung, and forestomach polycyclic aromatic hydrocarbon metabolism and tumorigenicity in Sencar mice. Cancer Res. 1989;21:5784-8. 
21. Scalbert A, Monties B, Janin G. Tannins in wood: comparison of different estimation methods. J Agric Food Chem. 1989;5:1324-9.

22. Khan NS, Ahmad A, Hadi SM. Anti-oxidant, pro-oxidant properties of tannic acid and its binding to DNA. Chem Biol Interact. 2000;3:177-89.

23. Haslam E. Vegetable tannins-lessons of a phytochemical lifetime. Phytochemistry. 2007;22-24:2713-21.

24. Padzik M, Hendiger EB, Chomicz L, Grodzik M, Szmidt M, Grobelny J, et al. Tannic acid-modified silver nanoparticles as a novel therapeutic agent against Acanthamoeba. Parasitol Res. 2018;11:3519-25.

25. Borase HP, Patil CD, Sauter IP, Rott MB, Patil SV. Amoebicidal activity of phytosynthesized silver nanoparticles and their in vitro cytotoxicity to human cells. FEMS Microbiol Lett. 2013;2:127-31.

26. Orlowski P, Tomaszewska E, Gniadek M, Baska P, Nowakowska J, Sokolowska J, et al. Tannic acid modified silver nanoparticles show antiviral activity in herpes simplex virus type 2 infection. PLOS ONE. 2014;9(8):e104113.

27. Aqeel Y, Siddiqui R, Anwar A, Shah MR, Khan NA. Gold nanoparticle conjugation enhances the antiacanthamoebic effects of chlorhexidine. Antimicrob Agents Chemother. 2015;3:1283-8.

28. Zielinska M, Sawosz E, Grodzik M, Wierzbicki M, Gromadka M, Hotowy A et al. Effect of heparan sulfate and gold nanoparticles on muscle development during embryogenesis. Int J Nanomed. 2011;6:3163-72.

29. McBride J, Ingram PR, Henriquez FL, Roberts CW. Development of colorimetric microtiter plate assay for assessment of antimicrobials against Acanthamoeba. J Clin Microbiol. 2005;2:629-34.

30. Radford CF, Minassian DC, Dart JK. Acanthamoeba keratitis in England and Wales: incidence, outcome, and risk factors. Br J Ophthalmol. 2002;5:536-42.

31. Codling CE, Maillard JY, Russell AD. Aspects of the antimicrobial mechanisms of action of a polyquaternium and an amidoamine. J Antimicrob Chemother. 2003:5:1153-8.

32. Santodomingo-Rubido J, Mori O, Kawaminami S. Cytotoxicity and antimicrobial activity of six multipurpose soft contact lens disinfecting solutions. Ophthalmic Physiol Opt. 2006;5:476-82.

33. Kal A, Toker MI, Kaya S. The comparison of antimicrobial effectiveness of contact lens solutions. Int Ophthalmol. 2017;5:1103-14.

34. Murthy SK. Nanoparticles in modern medicine: state of the art and future challenges. Int J Nanomed. 2007;2:129-41.

35. Shrivastava S, Bera T, Roy A, Singh G, Ramachandrarao P, Dash D. Characterization of enhanced antibacterial effects of novel silver nanoparticles. Nanotechnology. 2007;22:225103.

36. Roy A, Bulut O, Some S, Mandal AK, Yilmaz MD. Green synthesis of silver nanoparticles: biomolecule-nanoparticle organizations targeting antimicrobial activity. RSC Adv. 2019;5:2673-702.

37. Yan X, He B, Liu L, Qu G, Shi J, Hu L, et al. Antibacterial mechanism of silver nanoparticles in Pseudomonas aeruginosa: proteomics approach. Metallomics. 2018:4:557-64.

38. Bondarenko O, Juganson K, Ivask A, Kasemets K, Mortimer M, Kahru A. Toxicity of $\mathrm{Ag}, \mathrm{CuO}$ and $\mathrm{ZnO}$ nanoparticles to selected environmentally relevant test organisms and mammalian cells in vitro: a critical review. Arch Toxicol. 2013;7:1181-200

39. Behl G, Iqbal J, O'Reilly NJ, McLoughlin P, Fitzhenry L. Synthesis and characterization of poly(2-hydroxyethylmethacrylate) contact lenses containing chitosan nanoparticles as an ocular delivery system for dexamethasone sodium phosphate. Pharm Res. 2016;7:1638-48.

40. Liu S, Dozois MD, Chang CN, Ahmad A, Ng DL, Hileeto D, et al. Prolonged ocular retention of mucoadhesive nanoparticle eye drop formulation enables treatment of eye diseases using significantly reduced dosage. Mol Pharm. 2016;9:2897-905.

41. Willcox MDP, Hume EBH, Vijay AK, Petcavich R. Ability of silver-impregnated contact lenses to control microbial growth and colonisation. J Optometry. 2010;3:143-8.

42. Fazly Bazzaz BS, Khameneh B, Jalili-Behabadi MM, Malaekeh-Nikouei B, Mohajeri SA. Preparation, characterization and antimicrobial study of a hydrogel (soft contact lens) material impregnated with silver nanoparticles. Cont Lens Anterior Eye. 2014:3:149-52.

43. Amos CF, George MD. Clinical and laboratory testing of a silver-impregnated lens case. Cont Lens Anterior Eye. 2006;5:247-55.

44. Anwar A, Chi Fung L, Anwar A, Jagadish P, Numan A, Khalid M, et al. Effects of shape and size of cobalt phosphate nanoparticles against Acanthamoeba castellanii. Pathogens. 2019:4:10.
45. Anwar A, Mungroo MR, Anwar A, Sullivan WJ, Khan NA, Siddiqui R. Repositioning of guanabenz in conjugation with gold and silver nanoparticles against pathogenic amoebae Acanthamoeba castellanii and Naegleria fowleri. ACS Infect Dis. 2019;12:2039-46.

46. Grün A, Scheid P, Hauröder B, Emmerling C, Manz W. Assessment of the effect of silver nanoparticles on the relevant soil protozoan genus Acanthamoeba. J Plant Nutr Soil Sci. 2017;5:602-13.

47. Padzik M, Hendiger EB, Zochowska A, Szczepaniak J, Baltaza W, Pietruczuk-Padzik $A$, et al. Evaluation of in vitro effect of selected contact lens solutions conjugated with nanoparticles in terms of preventive approach to public health risk generated by Acanthamoeba strains. Ann Agric Environ Med. 2019;1:198-202.

48. Anwar A, Siddiqui R, Hussain MA, Ahmed D, Shah MR, Khan NA. Silver nanoparticle conjugation affects antiacanthamoebic activities of amphotericin B, nystatin, and fluconazole. Parasitol Res. 2018;1:265-71.

49. Anwar A, Numan A, Siddiqui R, Khalid M, Khan NA. Cobalt nanoparticles as novel nanotherapeutics against Acanthamoeba castellanii. Parasites Vectors. 2019;1:280

50. Nishanthi R, Malathi S, John Paul S, Palani P. Green synthesis and characterization of bioinspired silver, gold and platinum nanoparticles and evaluation of their synergistic antibacterial activity after combining with different classes of antibiotics. Mater Sci Eng. 2019;96:693-707.

51. Pirtarighat S, Ghannadnia M, Baghshahi S. Green synthesis of silver nanoparticles using the plant extract of Salvia spinosa grown in vitro and their antibacterial activity assessment. J Nanostructre Chem. 2019;1:1-9.

52. Bilal M, Zhao Y, Rasheed T, Ahmed I, Hassan STS, Nawaz MZ, et al. Biogenic nanoparticle chitosan conjugates with antimicrobial, antibiofilm, and anticancer potentialities: development and characterization. Int J Environ Res Public Health. 2019:4:10

53. Hamouda RA, Hussein MH, Abo-Elmagd RA, Bawazir SS. Synthesis and biological characterization of silver nanoparticles derived from the cyanobacterium Oscillatoria limnetica. Sci Rep. 2019;1:13071-y.

54. Kohan Baghkheirati E, Bagherieh-Najjar MB, Khandan Fadafan H, Abdolzadeh A. Synthesis and antibacterial activity of stable bio-conjugated nanoparticles mediated by walnut (Juglans regia) green husk extract. J Exp Nanosci. 2016;7:512-7.

55. Alomari AA, Kloub Fares KE, Moustafa NE. Green synthesis of assembled silver nanoparticles in nano capsules of Peganum harmala L. leaf extract. Antibacterial activity and conjugate investigation. Cogent Chem. 2018;4:1.

\section{Publisher's Note}

Springer Nature remains neutral with regard to jurisdictional claims in published maps and institutional affiliations.

Ready to submit your research? Choose BMC and benefit from:

- fast, convenient online submission

- thorough peer review by experienced researchers in your field

- rapid publication on acceptance

- support for research data, including large and complex data types

- gold Open Access which fosters wider collaboration and increased citations

- maximum visibility for your research: over $100 \mathrm{M}$ website views per year

At BMC, research is always in progress.

Learn more biomedcentral.com/submissions 